\title{
Ueber die quantitative Bestimmung des Koffeïns.
}

\author{
Von Dr. J. Katz in Dresden-Reudnitz (Autoreferat).
}

Von den bisher bekannten Koffeïnbestimmungsverfahren wurden diejenigen von Keller, Dieterich und Beitter bei rohem Kaffee, Guaranapaste und Kolanüssen bis zu einem gewissen Grade als brauchbar befunden, während dieselben bei gebranntem Kaffee, gebrannten Kolanüssen und Paraguaythee nicht anwendbar sind. Da diese Verfahren aber noch einige Uebelstände aufweisen, wurde das Beitter'sche als das brauchbarste der drei Verfahren in folgender Weise abgeändert:

$100 \mathrm{~g}$ der Droge werden mit $200 \mathrm{~g}$ Chloroform und $5 \mathrm{~g}$ Ammoniak eine halbe Stunde geschüttelt. Nach dem Absetzen der Flüssigkeit wird die Chloroformlösung durch ein Sander'sches Cigarettenfilter filtrirt, wobei mit Leichtigkeit 150,0 g eines völlig blanken und wasserfreien Filtrates erhalten werden. Das Filtrat wird durch Destillation vom Chloroform völlig befreit, der Rückstand in 5 ccm Aether gelöst (nöthigenfalls durch kürzeres Erwärmen am Rückflusskühler), $20 \mathrm{ccm} 0,5 \%$-ige Salzsäure und bei Kaffeebohnen etwa 0,5 g festes Paraffin zugefügt, der Aether verdunstet und die wässerige Flüssigkeit nach dem Erkalten filtrirt. Köllbchen und Filter werden noch einigemale mit kleinen Mengen 0,5\%-iger Salzsüure nachgewaschen und das saure wässerige Filtrat entweder im Perforator zwei Stunden lang mit Chloroform erscböpft; oder aber viermal im Scheidetrichter mit je $200 \mathrm{ccm}$ Chloroform ausgeschüttelt. Die Chloroformlösungen werden nöthigenfalls filtrirt und dann abdestillirt.

Die mit diesem Verfahren erhaltenen Ergebnisse werden für rohe Kaffeebobnen, schwarzen Thee, Guaranapaste und Kolanüsse mitgetheilt.

Bei dem Paraguaythee versagt aber auch dieses Verfahren insofern, als das Koffeïn nicht genügend rein erhalten werden kann; während die übrigen Verfahren beim Paraguaythee ganz unbrauchbar sind. Es wurde daher für Paraguaythee folgendes besondere Verfahren ausgearbeitet: Die Droge wird, wie oben beschrieben, mit Chloroform und Ammoniak behandelt, der Rückstand der Chloroformlösung in. Aether gelöst, der Aether nach Zugabe von $20 \mathrm{ccm}$ Wasser weggekocht und die wässerige Flüssigkeit mit $2 \mathrm{cem}$ einer Aufschüttelung von Bleihydroxyd in Wasser $(1: 20)$ und bei Kaffeebohnen etwa $0,5 \mathrm{~g}$ festem Paraffin 10 Minuten auf dem Wasserbade erwärmt. Darauf giebt man einjge Decigramme gebrannte Magnesia hinzu und filtrirt nach dem Erkalten. Das völlig klare, nur ganz schwach gefärbte Filtrat wird darauf im Perforator mit Chloroform erschöpft.

Das reinste Koffeïn erhält man, wenn man die nach Beitter's Verfahren erhaltene rohe, wässerige Koffeïnlösung mit Ammoniak versetzt, mit Chloroform erschöpft und das erhaltene Koffeĩn nach dem Trocknen nochmals in 0,5\%-iger Salzsäure löst und zum zweitenmale mit Chloroform extrahirt. Es wurden Beleganalysèn für die Exaktheit der besprochenen Verfahren, sowie dabei erbaltene Koffeìne vorgelegt.

\section{Versammlungen, Tagesneuigkeiten etc.}

Die 27. Versammlung des Deutschen Vereines fïr öffentliche Gesundheitspflege fand in den Tagen vom 17-19. September 1902 unter dem Vorsitze ron Prof. Dr. FrankelHalle a. S. und in Anwesenheit von etwa 600 Mitgliedern im Bayerischen Hof zu Manchen statt. 